\title{
Geochemical, structural and morphological characterization of vein graphite deposits of Sri Lanka: Witness to carbon rich fluid activity
}

\author{
H.P.T. Sasanka HewathilaKe ${ }^{* * *}$, N.W.B. BalasooriYa ${ }^{* * *}$, Yoshihiro NAKAMURA ${ }^{\dagger, \$}$, H.M.T.G.A. Pitawala** ${ }^{* *}$ \\ H.W.M. Athula Chandana WiJAYASINGHE* and M. SATISH-KUMAR \\ *National Institute of Fundamental Studies, Kandy, Sri Lanka \\ ${ }^{* *}$ Mineral Resources and Technology, Department of Science and Technology, Uva Wellassa University, Badulla, Sri Lanka \\ ${ }^{* * *}$ Department of Geology, Faculty of Science, University of Peradeniya, Peradeniya, Sri Lanka \\ ${ }^{\dagger}$ Graduate School of Science and Technology, Niigata University, Niigata 950-2181, Japan \\ ॠDepartment of Geology, Faculty of Science, Niigata University, Niigata 950-2181, Japan \\ ${ }^{\$}$ Present address: Geological Survey of Japan, AIST, Tsukuba, Ibaraki 305-8567, Japan
}

\begin{abstract}
Sri Lanka is endowed with high purity vein graphite deposits with extensive mineralization in the tectonically weakened zones of the basement high-grade rocks. Distinctly different crystal shapes of graphite are found even within a single vein and it is controversial in interpreting prevailed fluid activities and crystallization process to form such a variation. Therefore, this study was carried out to interpret the origin of vein graphite using geochemistry, crystal-morphology, and structure of the crystals. Sampling was conducted on four different depths at the Kahatagaha-Kolongaha mine, Sri Lanka. Characterizations of graphite were carried out by micro-Raman spectroscopy, X-ray diffraction spectroscopy, scanning electron microscopy, and inductive couple plasma mass spectroscopy. The results indicate that the genesis of the vein graphite is related to a single phase of fluid activity and the fluid was mostly pure with possible trace impurities. Further, it was revealed that the thickness of the veins, interaction with host rocks and mobility of the impurity elements have influenced the formation of different morphologies of graphite in a single vein.
\end{abstract}

Keywords: Vein graphite, Morphology, Crystallinity, Fluid activity, Impurity elements

\section{INTRODUCTION}

Graphite is an attractive industrial mineral that has a layered structure with sets of loosely stacked graphene layers. Naturally occurring graphite is typically classified into three forms, (i) microcrystalline graphite, (ii) flake graphite, and (iii) vein graphite (Wyckoff, 1963; Mitchell, 1993). Microcrystalline graphite deposits consist of small particles of graphite with impurities and they are associated with sub-greenschist facies to greenschist facies rocks formed by contact or regional metamorphism of coal seams (Taylor, 2006). Flaky type of graphite is typically found as disseminated platy particles in a variety of rocks such as marble, paragneiss, and quartzite

doi:10.2465/jmps. 170721

H.W.M.A.C. Wijayasinghe, athula@ifs.ac.lk Corresponding author which have been subjected to upper amphibolite to granulite facies metamorphism (Mitchell, 1993; Simandl et al., 1995). The economically most significant epigenetic vein graphite deposits are found in the metasedimentary belts, same as crystalline flake graphite deposits, which are metamorphosed to upper amphibolite and granulite facies. These vein graphite deposits consist of highly crystalline and chemically purest graphite (Simandl et al., 2015). Comparably these types of deposits are restricted to few occurrences such as those found in Sri Lanka, India, United States of America, and United Kingdom (Wijayananda, 1987; Luque et al., 2014).

Vein type graphite deposits in Sri Lanka have received more attention due to their high purity and high crystallinity as well as extensive mineralization (Erdosh, 1970; Hapuarachchi, 1977). They are the only vein graphite deposits which are currently being mined in 


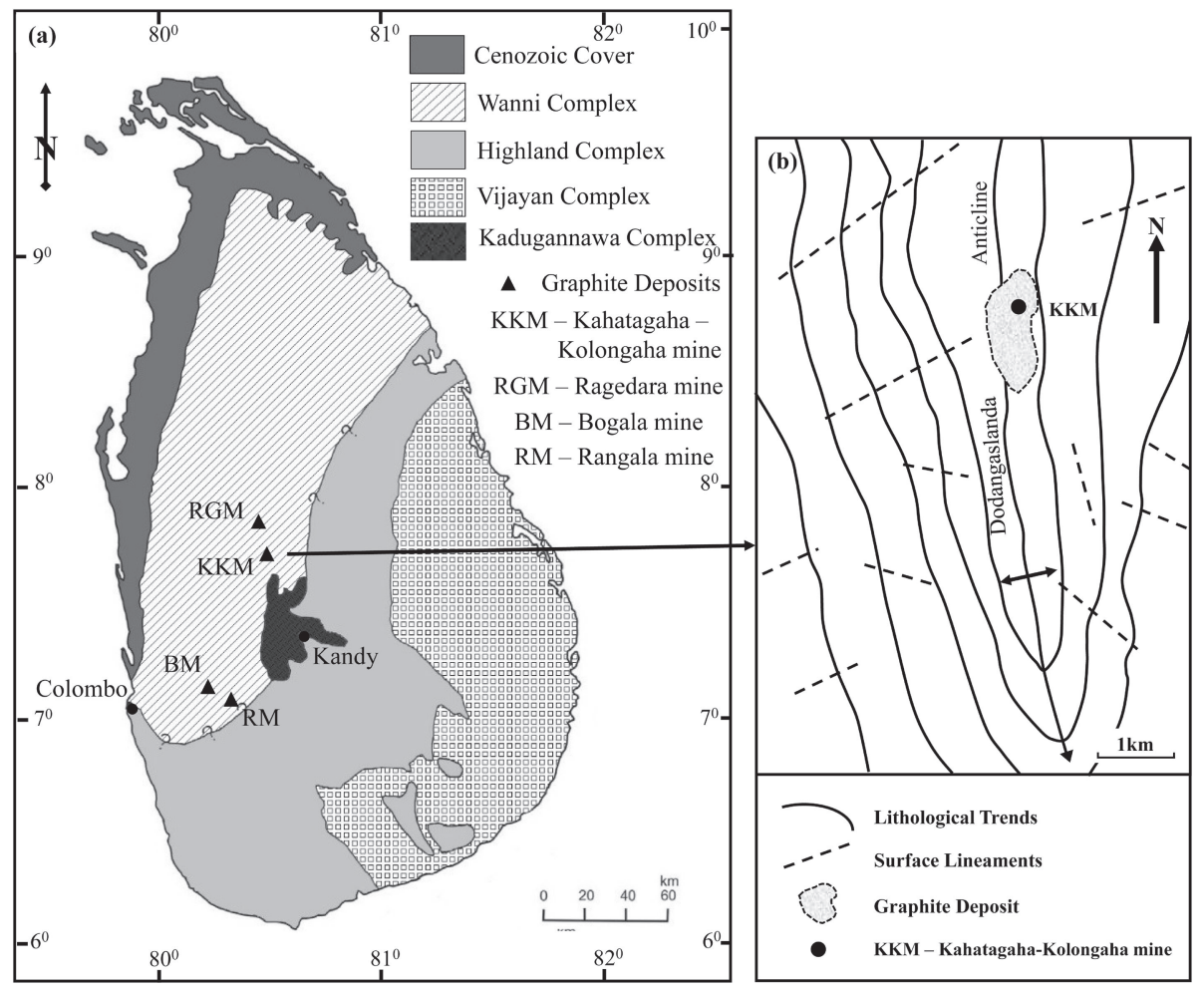

Figure 1. (a) Map showing major geological subdivisions of Sri Lanka (Cooray, 1994) with the locations of presently mining graphite deposits. (b) The geological structure of the Kahatagaha-Kolongaha graphite mine (after Silva, 1974). the world (Simandl et al., 2015). Most of Sri Lankan vein graphite deposits (see Fig. 1) occur in the Wanni Complex (WC) which is a Precambrian high-grade metamorphic terrain (Cooray, 1994; Binu-Lal et al., 2003).

Previous studies have shown that the vein deposits are usually restricted to antiformal or synformal structures and they are found close to axial traces of both antiforms and synforms (Silva, 1974; Kehelpannala, 1999). Such graphite veins crosscut the structures in the host basement rock randomly (Kehelpannala and Francis, 2001). The thickness of the veins varies from a few $\mathrm{mm}$ to several cm (Kehelpannala, 1995).

Graphite mineralization is associated with accessory minerals such as pyrite (Py), chalcopyrite (Ccp), sphalerite (Sp), marcasite (Mrc), calcite (Cal), dolomite (Dol), quartz $(\mathrm{Qz})$, and siderite $(\mathrm{Sd})$ which may be products of hydrothermal processes (Wijayananda and Jayawardana, 1983; Kehelpannala and Francis, 2001). Apart from them, minerals of the host rocks such as plagioclase ( $\mathrm{Pl}), \mathrm{K}$-feldspar (Kfs), garnet (Grt), hornblende ( $\mathrm{Hbl})$, and biotite $(\mathrm{Bt})$ are also found within graphite veins.

Six morphologically different varieties of vein graphite, namely, fibrous, flake, spherulitic, semispherulitic, finely crystalline, and recrystallized fine-grained graphite were identified in a previous study on Sri Lankan vein graphite (Kehelpannala, 1993). However, the number of varieties have been re-grouped into four in latest stud- ies, and they are named as needle-platy graphite (NPG), shiny-slippery-fibrous graphite (SSF), coarse striated-flaky graphite (CSF), and coarse flakes of radial graphite (CFR), based on their microstructural and physical characteristics (Balasooriya et al., 2002; Touzain et al., 2010). It is interesting to note that these different morphological types are found even within a single vein (Touzain et al., 2010; Hewathilake et al., 2015).

Revealing the genesis of the vein graphite is critical as it accounts for its high purity and mode of crystallization. Therefore, several studies were carried out to understand the possible sources of vein graphite (Hapuarachchi, 1977; Dissanayake, 1981, 1986; Katz, 1987; Silva, 1987). The summary of the findings of previous studies is given in Table 1.

Kehelpannala (1995) claimed that vein graphite deposits may have formed around 475-550 Ma ago and the source of carbon may be either magmatic fluid or a volatile phase emanating from the mantle. Touzain et al. (2010) suggested that a hydrothermal redox reaction between $\mathrm{CO}_{2}$ and $\mathrm{CH}_{4}$ escaping from a magmatic fluid may have caused the formation of Sri Lankan vein graphite. A recent study on the morphological variation of graphite carried out at Kahatagaha-Kolongaha mine suggested that the formation of vein graphite has resulted from either multi stage hydrothermal infiltration or due to different stages of crystallization (Hewathilake et al., 2015). 
Table 1. The summary of the previous studies explanation about the origin of Sri Lankan vein graphite

\begin{tabular}{ll}
\hline Cited reference & Explanation for the origin of Sri Lankan vein graphite \\
\hline Hapuarachchi,1977 & $\begin{array}{l}\text { The fluid rich in } \mathrm{CO}_{2} \text { derived from decarbonation reactions in calcareous environment may produce carbon } \\
\text { as a source for vein graphite formation. }\end{array}$
\end{tabular}

Dissanayake, 1981 and Dissanayake, 1986

Katz, 1987

Silva, 1987
An organic origin is postulated as a source of carbon. Subsequent deformation and magmatic activities mobilized the dispersed carbonaceous matter. Then graphitization may be completed while the carbon was suspended in the fluid phase and pressed it into a system of veins occupying parts of the anticlinal folds.

The graphite deposits of Sri Lanka are a direct consequence granulite facies metamorphism in the presence of a $\mathrm{CO}_{2}$ rich fluid under low $\mathrm{O}_{2}$ conditions. This $\mathrm{CO}_{2}$ rich fluid may promote hydraulic fracturing and precipitation of vein graphite. Further, textures and structures of the vein graphite indicate syntectonic deposition by a crack-seal process that confirm the granulite facies metamorphic conditions in the period of formation.

Vein-type mineralization occurs due to the deep-seated hydrothermal activity in the zones of fractures in supracrustal stratiform metasedimentary rocks. Decarbonation of carbonates and reduction of $\mathrm{CO}_{2}$ formed during the decarbonation reaction were contributed to the formation of vein graphite.
Despite many studies conducted on the source of vein graphite, accurate understanding of the dynamics of the carbon-rich fluid phase behavior in graphite deposition has not yet been clearly understood due to lack of information on the crystallinity, chemistry, and chronology of graphite deposits. Therefore, the present study is focused to interpret the fluid chemistry and condition of formation of vein graphite deposits in Sri Lanka.

\section{Geological setting of the study area and other hydro- thermal deposits}

Kahatagaha-Kolongaha deposit, which is one of the major graphite mines in Sri Lanka, was selected for this study. The major rock types in the mine area are quartzite, quartzo-feldspathic gneiss, garnet-cordierite-biotite gneiss, sillimanite-bearing gneiss, and calc-silicate gneiss, all of which have experienced granulite facies metamorphism. The veins occur along the East-West direction, cutting high-grade gneissic host rocks. In addition to Kahatagaha-Kolongaha graphite deposit, other major deposits such as Bogala and Ragedara are also located in the WC and also have similar types of graphite mineralization (Fig. 1).

On the other hand, economically important hydrothermal mineralizations in Sri Lanka are mica and vein quartz (Piumalee et al., 2013; Madugalla et al., 2015). These deposits are mostly restricted into the Highland Complex (HC). Similar to vein graphite deposits, most of the occurrences of vein quartz are characterized by irregular, short vein segments with clearly defined sharp contact to the wall rock. Geological and geophysical investigations revealed that the formation of Sri Lankan vein quartz is a single stage crystallization of a hydrothermal solution under fast cooling conditions (Piumalee et al., 2013). Although graphite and Qz deposits have been formed by the direct precipitation from fluids, mica mineralization has resulted from the hydrothermal alteration of host rock (Fernando et al., 2011).

\section{METHODS}

\section{Sampling}

Samples were collected from different veins at four different depths. The selected veins were located at 172, 345,585 , and $610 \mathrm{~m}$ levels in the mine. A1-A4, B1$\mathrm{B} 3, \mathrm{C} 1-\mathrm{C} 4$, and D1-D4 denote the sample numbers given for different morphological layers present in the four veins selected for detailed study. Before sampling, each vein was observed for the occurrence of different morphological varieties, size of the veins, their orientations, and gangue minerals (Fig. 2). Selected samples were crushed by a vibratory disk mill to particle size less than $53 \mu \mathrm{m}$, which used for further chemical analysis and other characterizations.

\section{Characterization}

Trace element analysis by using aqua-regia partial extraction was carried out for all the samples by Inductively Coupled Plasma Mass Spectroscopy (ICP-MS) (Perkin Elmer Sciex ELAN 9000). Scanning Electron Microscope (SEM) images were taken by EEVO/LS 15 ZEISS to observe the morphological and the structural features at the microscopic level. 

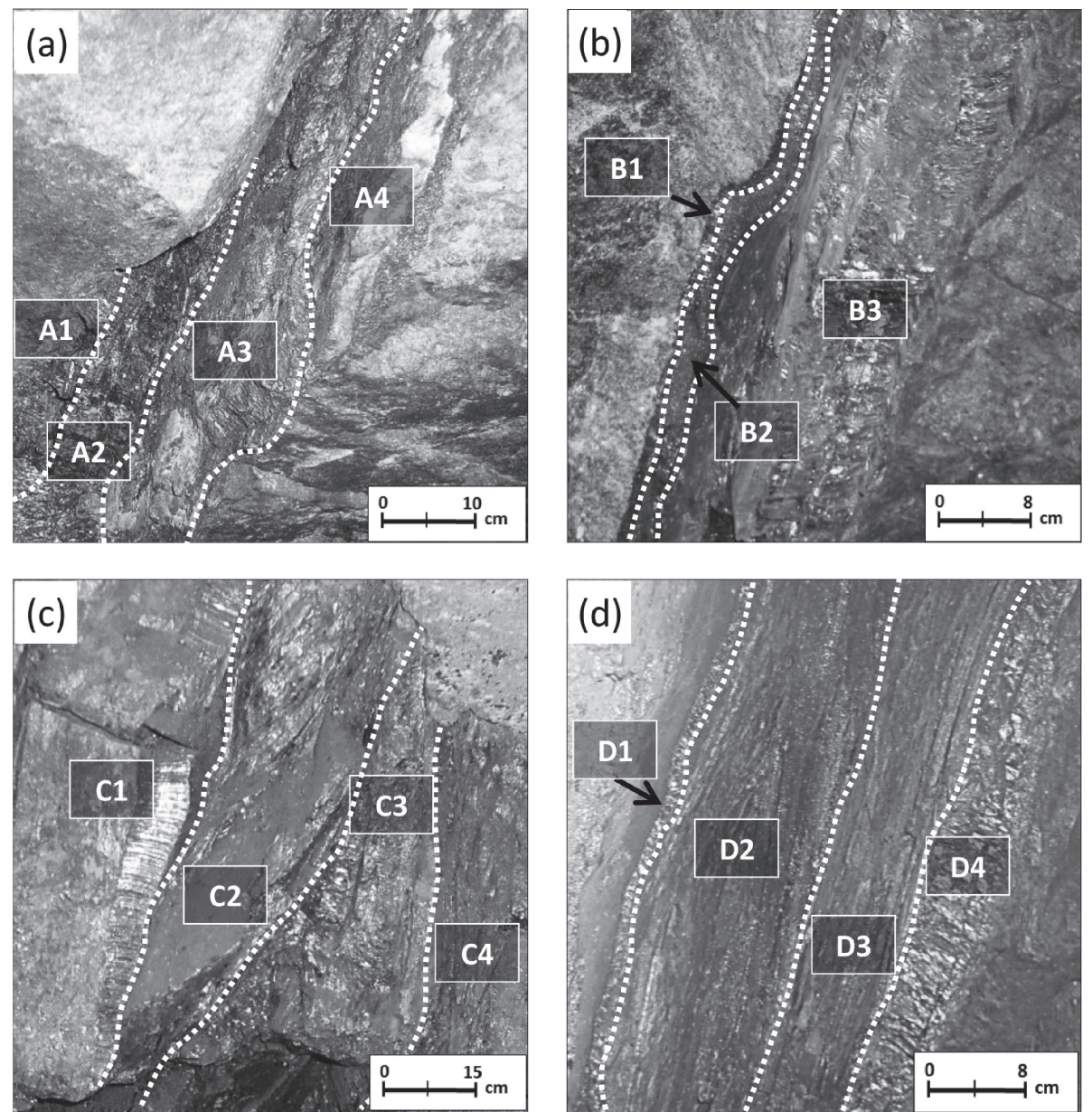

Figure 2. Four selected vein exposing areas for the sampling located at different depths. (a), (b), (c), and (d) are at $172,345,585$, and 610 m levels, respectively. A1-A4, B1$\mathrm{B} 3, \mathrm{C} 1-\mathrm{C} 4$, and D1-D4 indicate the identified different morphologies of graphite present with in each vein (Hewathilake et al., 2015).

X-Ray Diffraction (XRD) analysis was carried out using a Rigaku-Ultima IV X-ray diffractometer. Crystal size along $\boldsymbol{c}$-axis shows ' $L \boldsymbol{c}_{002}$ ', $\left[L \boldsymbol{c}_{002}(\AA)=(1 \times 1.5418) /\right.$ $\left.\left(\mathrm{FWHM}_{002} \times \cos \theta_{002}\right)\right]$, where $\mathrm{FWHM}_{002}$ stands for Full Width at Half Maximum of the (002) line (FWHM in rad.), $\lambda=1.5418 \AA$, and $\theta_{002}=$ Angle with reference to (002) line. R/H (\%) [Peak Area (101)R $/$ Peak Area A101)H $\times$ $100 \%$ ] and the degree of graphitization [D.G.\% $=(3.44$ $\left.\mathrm{d}_{002}\right) /(3.44-3.354) \times 100 \%$, where $\mathrm{d}_{002}$ is in $\AA$ ] (Iwashita et al, 2004; Touzain et al., 2010) were calculated from XRD data.

Micro-Raman spectroscopic analysis was performed with Jasco NRS 3100 housed at Niigata University. Mean value and standard deviation for the disordered peak D1 and ordered peak $G$ were calculated based on 10 analyses for each sample. $\mathrm{G}\left(\sim 1580 \mathrm{~cm}^{-1}\right), \mathrm{D} 1\left(\sim 1350 \mathrm{~cm}^{-1}\right), \mathrm{D} 2$ $\left(\sim 1600 \mathrm{~cm}^{-1}\right)$, and D3 $\left(\sim 1450 \mathrm{~cm}^{-1}\right)$ bands in the first order region $\left(1000-1800 \mathrm{~cm}^{-1}\right)$ were separated by peak profile fitting software. R1 ratio (Intensity 1 band/Intensity $\left._{\mathrm{G} \text { band}}\right)$, R2 ratio (Area $\left.\mathrm{D}_{\mathrm{D} \text { band }} / \mathrm{Area}_{\mathrm{G}+\mathrm{D} 1+\mathrm{D} 2 \text { band }}\right)$, and the crystal size of the lateral extent of carbon sheets ' $L_{a}$ ', $\left[L_{a}=\mathrm{C}(\lambda) / \mathrm{R} 1\right.$ ratio $\left.\mathrm{nm}\right]$ (Tuinstra and Koenig,
1970) were calculated according to the acquired band parameters. Furthermore, temperature conditions were calculated by $T^{\circ} \mathrm{C}=-445(\mathrm{R} 2)+641$ (Beyssac et al., 2002).

\section{RESULTS AND DISCUSSION}

\section{Morphological features}

Different morphologies of graphite as described by Balasooriya et al. (2002) and Touzain et al. (2010) could be observed in the field. It was noted that morphological variation of graphite does not depend on the depth of the formation, however such variation is present even within a single vein. Furthermore, narrow veins are strongly zoned with different types, however thicker veins are mostly restricted into two morphological varieties such as SSF and NPG. Veins with an average thickness of $20 \mathrm{~cm}$ generally contain four different morphologies (Fig. 3A). The layer attached to the wall rock is composed of fibrous type of graphite which are perpendicular to the vein direction. Pre-existing minerals such as Qz and Cal of the wall rocks may have acted as the nucleation aids for graphite and 

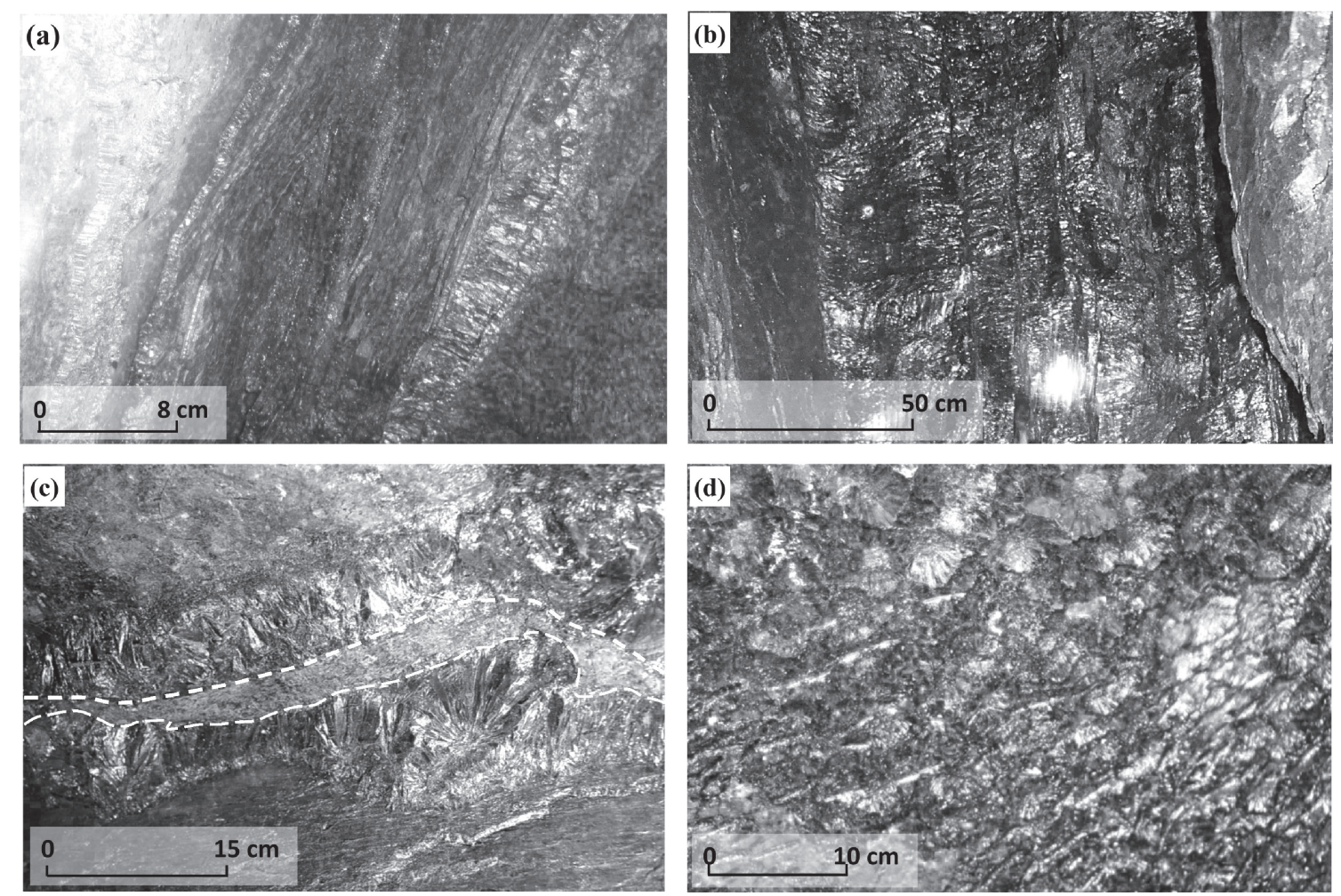

Figure 3. (a) and (b) formation of different morphological layers of graphite within a single vein. (c) and (d) wall rock interaction for the formation of graphite layers.

they have grown vertically since the number of nuclei was high and there was limited space for the lateral growth. However, the nucleation was less in the middle. Therefore, coarse-grained SSF and NPG morphologies could have formed symmetrically close to the middle of the vein.

Thicker veins $(100-120 \mathrm{~cm})$ contain only two different morphologies such as NPG and SSF in general (Fig. 3B). Notably, they are lacking the fine fibrous layers of graphite, but SSF morphological layer with $25-35 \mathrm{~cm}$ thickness can be observed in both sides of the vein. Middle of the vein is composed of 30-40 cm thick NPG layer (Balasooriya et al., 2002; Touzain et al., 2010). Since vein has formed in a large space, wall rock may not have influenced much during the crystallization process of carbon-rich source fluid.

The morphological zonation strongly depends on the vein thickness and the influence of the wall rock. However, XRD analysis in our previous study (Hewathilake et al., 2015) showed that all four morphologies have identical crystalline structure. Matsuura et al. (2007) compared XRD and thermo gravimetry-differential thermal analysis data and showed that all four morphologies are identical in crystalline structure, but they have different peak temperatures. Thus, these morphological variations are due to the minor structural changes of graphite during the progressive depositional process (Matsuura et al., 2007). Radiating fibrous formation of graphite is commonly found closer to the wall rock (Fig. 3C). It indicates that wall rock may have influenced on formation of different morphology of graphite. Alterations of wall rock due to fluid activity are found in many locations in the mine (Fig. 3D). This indicates that the higher temperature fluid has altered the surface of wall rocks, as described by Kehelpannala (1999).

In contrast to the visual observations (Balasooriya et al., 2002; Touzain et al., 2010), SEM study shows that the CFR grains are not fibrous, but they are platy grains arranged to form pyramidal shapes (Fig. 4A). SEM studies show that two different morphological layers such as SSF and NPG morphologies are not interlocked along their grain boundaries and they show sharp contacts with each other (Fig. 4B). It is suggested that graphite crystals in a single morphological layer did not affect the development of crystals in the neighboring layer. Similar features can be observed in Figure 4A, between CFR and SSF.

On the other hand, thick fibers of graphite with sharp edges are common in SSF morphology type (Figs. 4B and $4 C)$. NPG type of graphite occurred mostly parallel to the vein direction. In contrast, the SSF morphology is perpendicular to the vein (Fig. 4B). Graphite layers in NPG morphology are very closely packed and they form layers with 

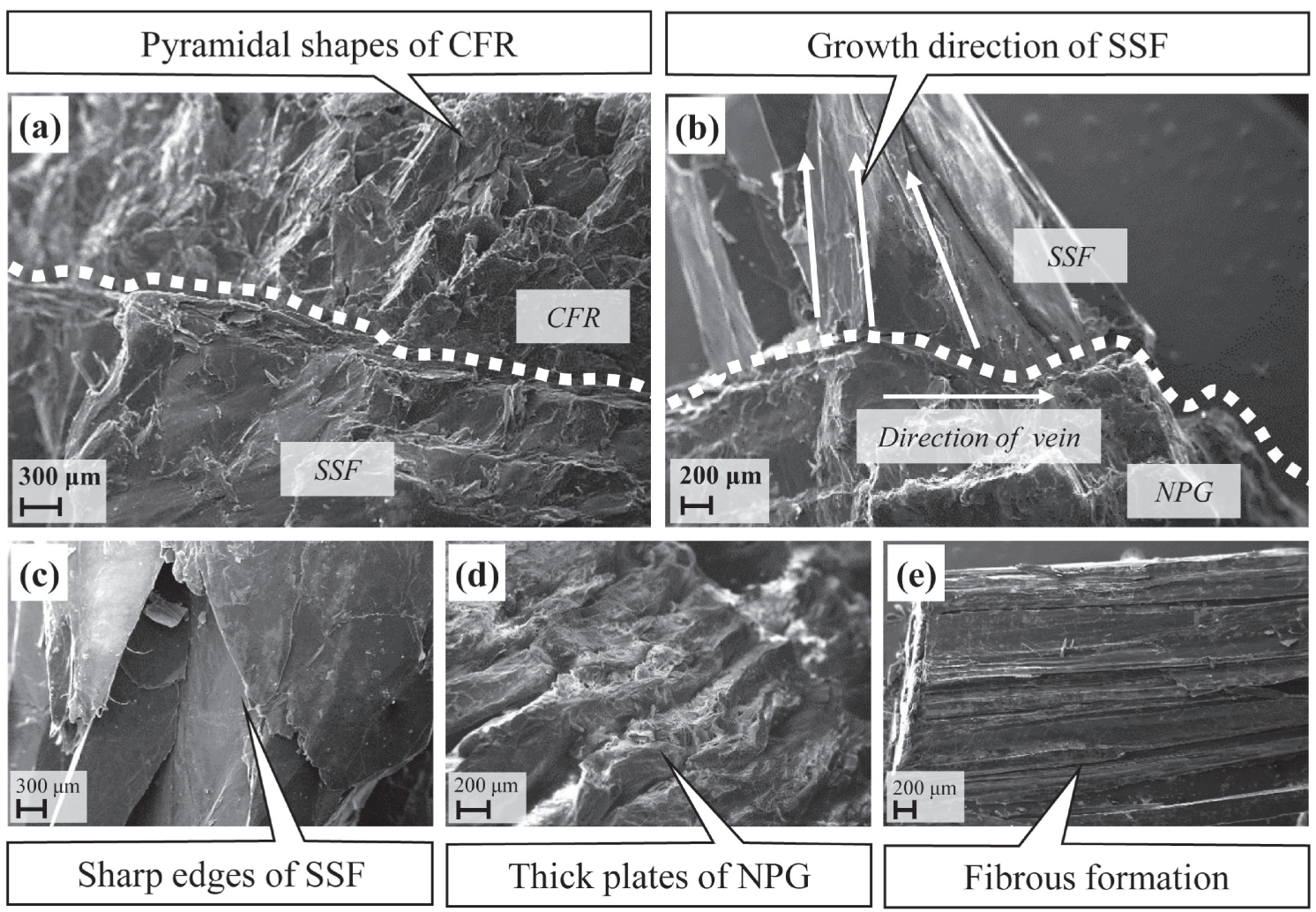

Figure 4. SEM images of the different morphologies in the contact zone and directions of the formation. (a) CFR/SSF, (b) SSF/NPG margin, (c) nature of SSF, (d) NPG, and (e) fibrous of type vein graphite.

fibrous nature of such morphology, which is also found, especially close to the wall rock (Fig. 4D). More fibrous nature can be observed in the SEM images than that of visual observation, for the graphite layer, readily attached to the wall rock (Fig. 4E) which indicates the rapid cooling conditions.

\section{Chemical composition}

Table 2 summarized the chemical analysis of different graphite morphologies. Concentrations of $\mathrm{Na}, \mathrm{Mg}, \mathrm{Ca}$, and $\mathrm{Fe}$ are relatively high compared to those of $\mathrm{Cr}$, $\mathrm{Mn}, \mathrm{Co}, \mathrm{Ni}, \mathrm{Cu}, \mathrm{Zn}, \mathrm{Sr}$, and $\mathrm{Ba}$.

Since vein graphite commonly contains Py, Ccp, and Sd (Kehelpannala, 1999; Touzain et al., 2010), the inclusions of such minerals may have contributed for higher levels Fe. Sodium ( $\mathrm{Na}$ ) concentrations do not show any significant variation among the samples. Higher contents of $\mathrm{Ca}$ and $\mathrm{Mg}$ notably closer to the wall rock region indicates that element exchanges between source fluid and wall rock has occurred. The presence of minerals like chlorite (Chl), Bt, and $\mathrm{Hbl}$ along the boundary of the veins confirm that hydrothermal alteration has occurred (Kehelpannala and Francis, 2001).

Copper is the prominent trace element, which has been contributed by Ccp in graphite (Hewathilake et al., 2015). Concentrations of $\mathrm{Ba}$ and Co do not vary much within the veins or at different depths. It was noted that the variation of concentrations of other elements is negligible. Variation of $\mathrm{Fe}$ and $\mathrm{Cu}$ in studied samples should be the result of unequal distribution of their sulfide minerals (Hewathilake et al., 2015). Chemical results indicate that the veins are mostly homogenous except near the vicinity of the wall rock zone. It is implying the single stage of carbon-rich fluid infiltration into the fractured rock. Furthermore, the source fluid was low in impurity elements.

\section{Crystallinity of different morphologies}

Table 3 summarizes the XRD results of each layer of graphite veins located at different depths. Interlayer space $\left(\mathrm{d}_{002}\right)$ of different morphologies of graphite in the veins, varies 3.354-3.384 $\AA$. The crystal size along $\boldsymbol{c}$-axis $\left(L_{C}\right)$ and degree of graphitization (D.G\%) exhibit an increasing trend towards shallow depth, however such variation does not depend on the morphology. Further, these parameters confirm the highly ordered crystalline structure of the vein graphite.

Homogeneity of crystallographic parameters irre- 
Table 2. Major and trace element composition of analyzed samples

\begin{tabular}{|c|c|c|c|c|c|c|c|c|c|c|c|c|c|}
\hline \multirow{2}{*}{$\begin{array}{r}\text { Depth } \\
(\mathrm{m})\end{array}$} & \multirow{2}{*}{$\frac{\text { Layer }}{\text { ID }}$} & \multicolumn{4}{|c|}{$\%$} & \multicolumn{8}{|c|}{ ppm } \\
\hline & & $\mathrm{Na}$ & $\mathrm{Mg}$ & $\mathrm{Ca}$ & $\mathrm{Fe}$ & $\mathrm{Cr}$ & $\mathrm{Mn}$ & Co & $\mathrm{Ni}$ & $\mathrm{Cu}$ & $\mathrm{Zn}$ & $\mathrm{Sr}$ & $\mathrm{Ba}$ \\
\hline \multirow{4}{*}{172} & $\mathrm{Al}$ & 0.01 & 0.03 & 0.04 & 0.11 & 7.2 & 3.3 & 0.8 & 8.6 & 41.1 & 1.4 & 4.1 & 6.5 \\
\hline & $\mathrm{A} 2$ & 0.01 & b.d. & 0.02 & 0.02 & 2.1 & 2.4 & 0.5 & 5.3 & 19.0 & 0.7 & 2.4 & 5.5 \\
\hline & A3 & 0.01 & 0.01 & 0.03 & 0.02 & b.d. & 7.9 & 1.2 & 9.7 & 9.8 & 1.2 & 4.3 & 5.5 \\
\hline & $\mathrm{A} 4$ & 0.02 & 0.02 & 0.05 & 0.11 & b.d. & 5.1 & 1.9 & 14.1 & 19.3 & 3.6 & 4.9 & 5.4 \\
\hline \multirow{3}{*}{345} & B1 & 0.02 & 0.02 & 0.33 & 0.07 & 1.4 & 109.0 & 1.9 & 19.5 & 40.9 & 5.8 & 3.6 & 6.7 \\
\hline & B2 & 0.02 & b.d. & 0.05 & 0.04 & b.d. & 15.1 & 1.2 & 10.3 & 59.5 & 3.9 & 0.5 & 5.8 \\
\hline & B3 & 0.02 & 0.02 & 0.04 & 0.05 & 1.1 & 11.2 & 0.5 & 4.3 & 20.6 & 1.4 & 1.7 & 5.1 \\
\hline \multirow{4}{*}{585} & $\mathrm{C} 1$ & 0.01 & 0.03 & 0.01 & 0.09 & 2.5 & 4.1 & 0.1 & 0.9 & 6.8 & 11.3 & 0.6 & 4.9 \\
\hline & $\mathrm{C} 2$ & 0.01 & b.d. & 0.01 & 0.01 & b.d. & 1.5 & 0.1 & 0.4 & 3.8 & 3.3 & b.d. & 5.9 \\
\hline & $\mathrm{C} 3$ & 0.04 & b.d. & 0.01 & 0.11 & b.d. & 4.6 & 0.7 & 3.0 & 25.1 & 1.3 & 1.1 & 5.5 \\
\hline & $\mathrm{C} 4$ & 0.01 & b.d. & b.d. & 0.03 & 4.7 & 1.4 & 0.2 & 0.6 & 15.4 & 3.9 & b.d. & 5.4 \\
\hline \multirow{4}{*}{610} & D1 & 0.01 & 0.01 & 0.03 & 0.02 & b.d. & 5,2 & 0.3 & 3.2 & 16.2 & 1.7 & 3.0 & 5.3 \\
\hline & D2 & 0.01 & 0.02 & 0.17 & 0.14 & b.d. & 34.4 & 1.9 & 16.4 & 82.3 & 0.8 & 2.4 & 5.1 \\
\hline & D3 & 0.01 & 0.03 & 0.07 & 0.43 & 1.1 & 22.3 & 3.3 & 25.6 & 162 & 0.9 & 2.3 & 5.5 \\
\hline & D4 & 0.02 & 0.05 & 0.06 & 0.74 & 1.3 & 41.1 & 6.4 & 49.1 & 148 & 1.8 & 2.1 & 5.2 \\
\hline
\end{tabular}

b.d., below detection limits.

Table 3. X-Ray Diffraction results for each layer of the veins

\begin{tabular}{cccccc}
\hline $\begin{array}{c}\text { Depth } \\
(\mathrm{m})\end{array}$ & $\begin{array}{c}\text { Layer } \\
\text { ID }\end{array}$ & $\begin{array}{c}\mathrm{d}_{002} \\
(\AA)\end{array}$ & $\begin{array}{c}L_{C 002} \\
(\mathrm{~nm})\end{array}$ & $\begin{array}{c}\mathrm{D} . \mathrm{G} \\
(\%)\end{array}$ & $\begin{array}{c}\mathrm{R} / \mathrm{H} \\
(\%)\end{array}$ \\
\hline \multirow{3}{*}{172} & A1 & 3.360 & 34.08 & 91.98 & 19.6 \\
& A2 & 3.360 & 32.46 & 91.98 & 18.1 \\
& A3 & 3.356 & 31.27 & 97.67 & 25.9 \\
& A4 & 3.360 & 32.17 & 91.98 & 34.1 \\
& B1 & 3.360 & 33.68 & 91.98 & 19.2 \\
345 & B2 & 3.358 & 28.49 & 94.77 & 29.6 \\
& B3 & 3.360 & 31.40 & 91.98 & 22.2 \\
& & & & & \\
& C1 & 3.354 & 25.79 & 99.15 & 20.0 \\
585 & C2 & 3.369 & 21.15 & 81.77 & 13.3 \\
& C3 & 3.369 & 24.47 & 81.77 & 23.7 \\
& C4 & 3.377 & 25.72 & 73.02 & 13.2 \\
& & & & & \\
& D1 & 3.365 & 24.04 & 86.13 & 18.2 \\
610 & D2 & 3.373 & 25.46 & 77.40 & 11.6 \\
& D3 & 3.384 & 26.01 & 64.23 & 19.4 \\
& D4 & 3.373 & 25.63 & 77.40 & 27.3 \\
\hline
\end{tabular}

spective of different morphological layers at the different depths tend to prove that the formation of the Sri Lankan vein graphite formed under a single-phase of carbon-rich fluid activity under different temperature and pressure conditions.

Table 4 summarizes the Raman spectroscopic analysis data of four different sampling locations. Almost all studied samples show high crystalline nature according to Raman bands of ordered peak $\mathrm{G}\left(\sim 1580 \mathrm{~cm}^{-1}\right)$ and dis- ordered peak D1 $\left(1350 \mathrm{~cm}^{-1}\right)$.

The length of carbon sheets $(L a)$ varies within a considerable range of 37-83 nm. Furthermore, it shows a noticeable variation among the different morphological layers within the same vein. Based on the recent categorization of different morphologies of vein graphite, $L a$ of the SSF morphology varies 96-141 nm (Touzain et al., 2010). Nevertheless, in this study the SSF morphology have $L a$ between 51-78 nm and NPG morphologies have 49-83 nm.

Typically, a D1 band of graphite is attributed to the structural defect in stacking (Pimenta et al., 2007) and doublet peaks of 2D1 clearly display a 3D graphite structure (Galvez et al., 2013). Figure 5 shows the two Raman spectrums of the same graphite sample. Though, the spectrum responsible for the edge plane possesses higher intensity D1 band compared to the spectrum of the middle basal plane of the same sample, the asymmetric appearance of the 2D1-peak in both spectrums is confirmed the highly ordered nature of the graphite. Both Raman spectrums prove the highly crystalline nature of the Sri Lankan vein graphite as previously reported by Luque et al. (2014).

R1 [intensity (D1 band)/intensity ( $\mathrm{G}$ band)] and FWHM of G band are the two parameters which can explain the degree of graphitization. These values changes if the degree of graphitization is low, For example, in the case of low grade metamorphic rocks of Hidaka metamorphic belt the $\mathrm{R} 1$ ratio changes from 0.1 to 1.5 , and the FWHM of G band from 18 to $35 \mathrm{~cm}^{-1}$ (Nakamura et 
Table 4. Micro-Raman Spectroscopic results for the different morphological layers

\begin{tabular}{|c|c|c|c|c|c|c|c|c|c|c|c|c|c|c|c|}
\hline $\begin{array}{l}\text { Depth } \\
\text { (m) }\end{array}$ & $\begin{array}{c}\text { Sample } \\
\text { ID }\end{array}$ & $\begin{array}{l}\text { D1 band } \\
\left(\mathrm{cm}^{-1}\right)\end{array}$ & $1 \sigma$ & $\begin{array}{l}\text { D1 band } \\
\text { FWHM }\end{array}$ & $1 \sigma$ & $\begin{array}{l}\text { G band } \\
\left(\mathrm{cm}^{-1}\right)\end{array}$ & $1 \sigma$ & $\begin{array}{l}\text { G band } \\
\text { FWHM }\end{array}$ & $1 \sigma$ & R1 & $1 \sigma$ & $\mathrm{R} 2$ & $1 \sigma$ & $\begin{array}{c}\mathrm{La} \\
(\mathrm{nm})\end{array}$ & $T\left({ }^{\circ} \mathrm{C}\right)$ \\
\hline \multirow{4}{*}{172} & Al & 1346.99 & 1.23 & 44.09 & 0.88 & 1577.61 & 1.41 & 16.73 & 1.43 & 0.11 & 0.05 & 0.19 & 0.06 & 42 & 555.3 \\
\hline & $\mathrm{A} 2$ & 1345.16 & 1.82 & 44.93 & 1.38 & 1575.99 & 2.38 & 16.96 & 1.68 & 0.12 & 0.04 & 0.22 & 0.05 & 37 & 544.8 \\
\hline & $\mathrm{A} 3$ & 1347.04 & 1.09 & 41.06 & 5.31 & 1578.72 & 1.31 & 15.03 & 2.11 & 0.09 & 0.06 & 0.17 & 0.09 & 51 & 565.1 \\
\hline & A4 & 1342.05 & 1.58 & 45.53 & 1.28 & 1576.33 & 2.98 & 15.03 & 1.28 & 0.07 & 0.02 & 0.16 & 0.03 & 65 & 570.4 \\
\hline \multirow{3}{*}{345} & B1 & 1340.03 & 1.24 & & & 1579.74 & 0.95 & & & & 0.04 & & & 51 & 563.5 \\
\hline & B2 & 1347.45 & 2.25 & & 2.52 & 1579.24 & 2.8 & & 1.5 & 0.07 & 0.05 & 0.15 & 0.08 & 61 & 574.6 \\
\hline & B3 & 1347.14 & 1.74 & 42.54 & 1.26 & 1579.11 & 1.84 & 14.45 & 1.63 & 0.05 & 0.03 & 0.12 & 0.06 & 83 & 586.2 \\
\hline \multirow{4}{*}{585} & $\mathrm{C} 1$ & 1347.07 & 2.68 & & 1.94 & 1578.69 & 3.8 & 14.99 & 1.48 & 0.06 & 0.03 & 0.13 & 0.05 & 78 & 584.4 \\
\hline & $\mathrm{C} 2$ & 1348.7 & 0.49 & 42.43 & 3.05 & 1580.82 & 0.5 & 15.75 & 2.05 & 0.09 & 0.06 & 0.17 & 0.09 & 49 & 566.4 \\
\hline & $\mathrm{C} 3$ & 1345.71 & 2.55 & 45.07 & 5.18 & 1576.99 & 3.46 & 15.72 & 1.34 & 0.08 & 0.04 & 0.18 & 0.07 & 52 & 562.3 \\
\hline & $\mathrm{C} 4$ & 1347.32 & 1.28 & 43.81 & 2.42 & 1578.7 & 1.67 & 15.38 & 1.88 & 0.07 & 0.04 & 0.16 & 0.07 & 60 & 569.9 \\
\hline \multirow{4}{*}{610} & D1 & 1346.22 & 1.72 & & 2.43 & 1577.79 & 1.86 & 15.81 & 1.74 & 0.07 & 0.04 & 0.14 & 0.06 & 64 & 579.3 \\
\hline & D2 & 1345.66 & 2.36 & 43.39 & 1.86 & 1577.33 & 3.31 & 14.8 & 0.9 & 0.07 & 0.04 & 0.15 & 0.08 & 66 & 576.1 \\
\hline & D3 & 1345.48 & 3.32 & 44.12 & 2.64 & 1577.91 & 1.91 & 15.81 & 2.68 & 0.07 & 0.04 & 0.14 & 0.06 & 67 & 579.2 \\
\hline & D4 & 1346.89 & 1.53 & 41.17 & 5.44 & 1579.24 & 2.2 & 14.8 & 1.09 & 0.07 & 0.03 & 0.15 & 0.06 & 65 & 574.5 \\
\hline
\end{tabular}

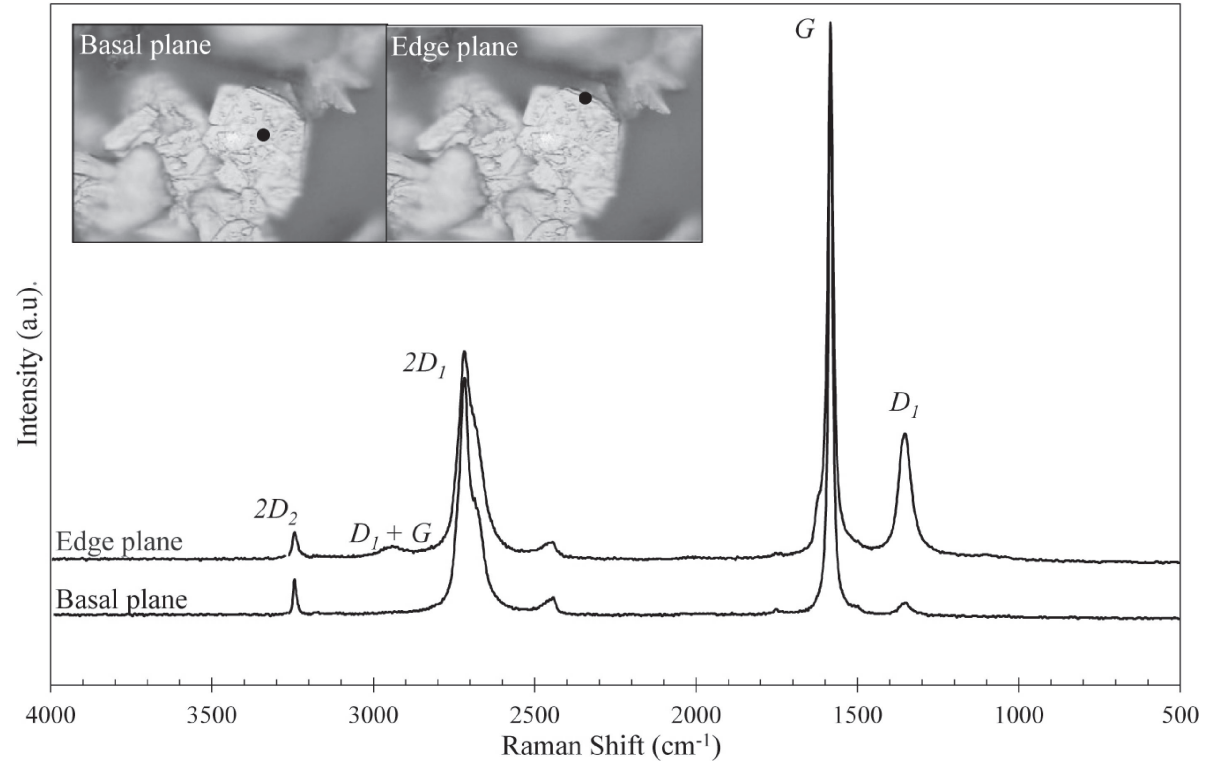

Figure 5. Micro Raman spectroscopic analysis of the edge plan and middle basal plan of the same vein graphite samples. al., 2015). The relationship between R1 and FWHM of $\mathrm{G}$ band (Fig. 6) for the four structural varieties collected from different localities of the studied mine, are compared with the disseminated metamorphic graphite from Hidaka metamorphic belt, Hokkaido, Japan (Nakamura et al., 2015). It clearly shows that the R1 and FWHM of G band values for Sri Lankan vein graphite are clustered in a narrow range (R1: $0.05-0.15$ and FWHM of G band: 14-18 $\mathrm{cm}^{-1}$ ), whereas the metamorphic graphite has a broad range (R1: from 0.05 -over 2.0 and FWHM of $G$ band: $16-45 \mathrm{~cm}^{-1}$ ) (Fig. 6A). Therefore, Sri Lankan vein graphite has a higher degree of graphitization than the metamorphic graphite formed at similar $P-T$ conditions. Since R1 ratio greatly depends on the intensity of the D1 band, the recorded low values for the $\mathrm{R} 1$ ratio explain that the relative amounts of edge planes in the carbon sheets are less, and there was no major deformation accompanying the formation of Sri Lankan vein graphite (Lespade et al., 1982).

The relationship between $\mathrm{R} 1$ and $\mathrm{R} 2$ ratio of four 

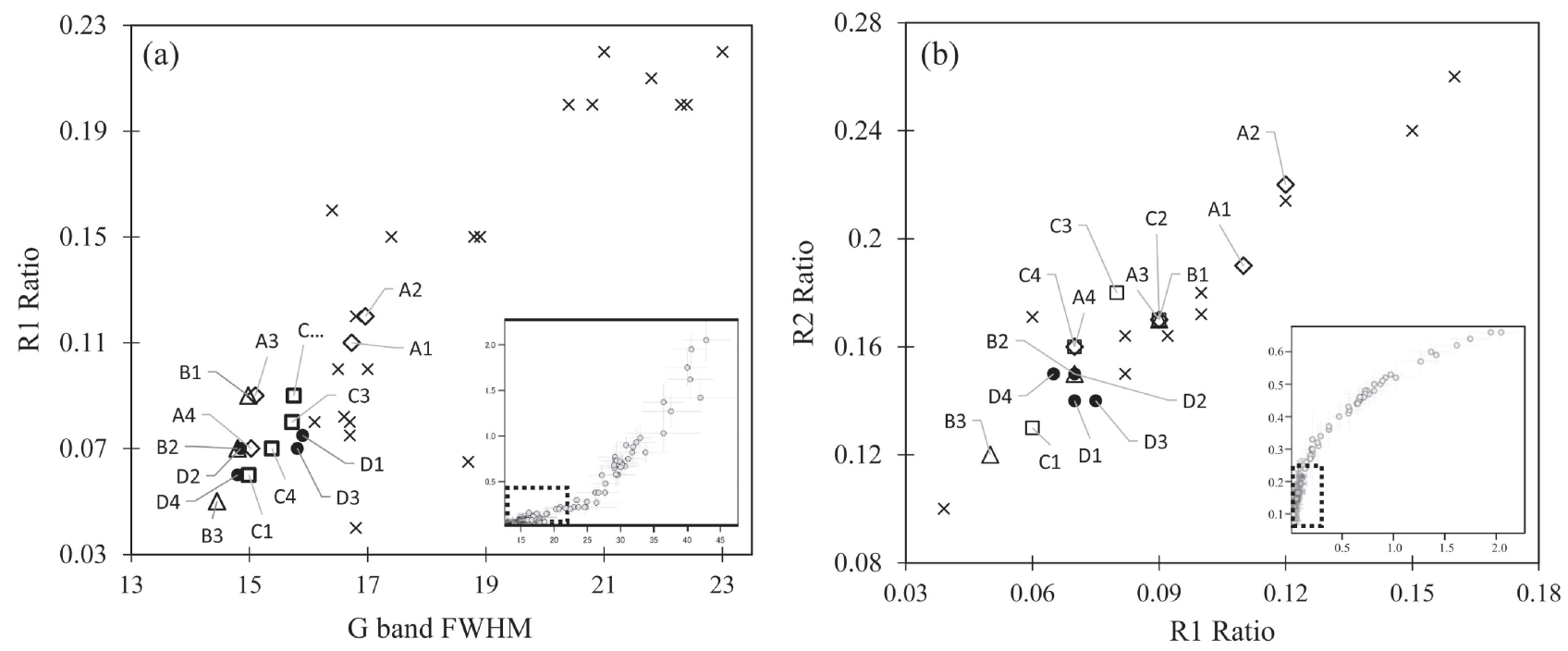

$\diamond$ Samples (A1 - A4) from 172 m level

$\Delta$ Samples (B1 - B3) from $345 \mathrm{~m}$ level

口 Samples (C1 - C4) from $585 \mathrm{~m}$ level

- Samples (D1 - D4) from $610 \mathrm{~m}$ level

X Samples from Hidaka metamorphic belt Hokkaido, Japan

Figure 6. (a) Comparison of the relationship between R1 ratio and FWHM of G band and (b) the relationship between R1 and R2 ratios of four different morphologies of Sri Lankan vein graphite and graphite samples from Hidaka metamorphic belt, Hokkaido, Japan.

main structural varieties of Sri Lankan vein graphite and graphite samples from Hidaka metamorphic belt, Hokkaido, Japan were compared (Fig. 6B). R2 is the most sensitive parameter for the crystalline defects (Beyssac et al., 2002). The R2 ratio for the analyzed Sri Lankan vein graphite was limited to the maximum of 0.22 , whereas metamorphic graphite exceeded 0.6. Furthermore, R2 ratio decreases with increasing depth and form a linear relationship with R1. Accordingly, the formation temperature has a narrow range from 540 to $585{ }^{\circ} \mathrm{C}$ for the collected samples at each depth. R1 and R2 ratio behavior together with the temperature variation indicates that the vein graphite formation in a single thermal event.

\section{CONCLUSION}

Mineralogical and chemical data of the present study revealed that graphite veins are homogeneous in terms of their chemistry. However, along the wall rock boundaries, the chemical composition of graphite is variable as a result of fluid-rock interactions. The results of this study suggest that the Sri Lankan vein graphite is highly crystalline with minimum crystalline defects. From boundaries towards the center of veins, different morphological varieties of graphite crystals have symmetrically formed. It may be due to the influence of wall rock and the variable extent of fracture spaces of the basement rocks. Higher degree of graphitization, narrow range of crystallization temperature of graphite, and their comparable chemical composition suggest that the graphite veins have been formed by a single phase of hydrothermal activity.

\section{ACKNOWLEDGMENTS}

The Kahatagaha-Kolongaha mines of Sri Lanka and the financial assistance from Innovative Research Grant2013 of University Grant Commission (UGC), Ministry of Higher Education, Sri Lanka are acknowledged. We thank the reviewers and the editor Toshiaki Tsunogae for valuable suggestions that improved the manuscript considerably. M. S-K acknowledges financial support No. JP15H05831 from the Ministry of Education, Culture, Sports, Science and Technology, Japan.

\section{REFERENCES}

Balasooriya, N.W.B., Dahanayake, K., Touzain, PH. and Bandaranayake, P.W.S.K. (2002) Structure characteristics of Sri Lanka graphite. Ceylon Journal of Science (Physical Sciences), 9, 41-48.

Beyssac, O., Chopin, C., Rouzaud, J.N. and Goffe, B. (2002) Ra- 
man spectra of carbonaceous material in metasediments: a new geothermometer. Journal of Metamorphic Geology, 20, 859-871.

Binu-Lal, S.S., Kehelpannala, K.V.W., Sathish-Kumar, M. and Wada, H. (2003) Multistage graphite precipitation through protracted fluid flow in sheared metagranitoid, Digana, Sri Lanka: evidence from stable isotopes. Journal of Chemical Geology, 197, 253-270.

Cooray, P.G. (1994) The Precambrian of Sri Lanka, A historic review. Precambrian Research, 66, 3-18.

Dissanayake, C.B. (1981) The origin of graphite of Sri Lanka. Journal of Organic Geochemistry, 3, 1-7.

Dissanayake, C.B. (1986) The origin of vein graphite of Sri Lanka: biogenic or abiogenic. L.J.D. Fernando Felicitation Volume, Geological Society of Sri Lanka, 131-140.

Erdosh, D. (1970) Geology of Bogala mine, Ceylon and the origin of vein type graphite. Mineral Deposita, 5, 375-382.

Fernando, G.W.A.R., Pitawala, A. and Amaraweera, T.H.N.G. (2011) Emplacement and evolution history of pegmatites and hydrothermal deposits, Matale District, Sri Lanka. International Journal of Geosciences, 2, 348-362.

Galvez, M.E., Beyssac, O., Martinez, I., Benzerara, K., Chaduteau, C., Malvoisin, B. and Malavieille, J. (2013) Graphite formation by carbonate reduction during subduction. Nature Geoscience, 6, 473-477.

Hapuarachchi, D.J.A.C. (1977) Decarbonation Reactions and the origin of vein graphite in Sri Lanka. Journal of the National Science Council of Sri Lanka, 5, 29-32.

Hewathilake, H.P.T.S., Balasooriya, N.W.B., Pitawala, H.M.T.G.A. and Wijayasinghe, H.W.M.A.C. (2015) Use of crystal morphologies to unravel the origin of vein graphite in Sri Lanka. Journal of Geological Society of Sri Lanka, 17, 65-73.

Iwashita, N., Park, C.R., Fujimoto, H., Shiraishi, M. and Inagaki, M. (2004) Specification for a standard procedure of X-ray diffraction measurements on carbon materials. Carbon, 42, 701714.

Katz, M.B. (1987) Graphite deposits of Sri Lanka: a consequence of granulite facies metamorphism. Mineral Deposita, 22, 1825.

Kehelpannala, K.V.W. (1993) Structural Evolution in the Area Surrounding the Kahatagaha-Kolongaha Graphite Mines, N-NW of Kandy, and the Origin of Vein Graphite in Sri Lanka. Ph.D. thesis, The University of Mainz, Germany.

Kehelpannala, K.V.W. (1995) Origin of Vein Graphite in Sri Lanka-Another View. In Handbook on Geology and Mineral Resources of Sri Lanka (Dahanayake, K. Ed.). Colombo, Sri Lanka, 95-103.

Kehelpannala, K.V.W. (1999) Epigenetic Vein Graphite Mineralization in the Granulite Terrain of Sri Lanka. Gondwana Research, 2, 654-657.

Kehelpannala, K.W. and Francis, M.D.L. (2001) Vein graphite deposits of the Kegalle District, Sri Lanka: further evidence for post-metamorphic, fluid-deposited graphite. Gondwana Research, 4, 655-656

Lespade, P., Al-Jishi, R. and Dresselhaus, M.S. (1982) Model for Raman scattering from incompletely graphitized carbons. Journal of Carbon, 20, 427-431.

Luque, F.J., Huizenga, J.M., Crespo-Feo, E., Wada, H., Ortega, L. and Barrenechea, J.F. (2014) Vein graphite deposits: geological settings, origin and economic significance. Mineral Deposita, 49, 261-277.
Madugalla, T.B.N.S., Pitawala, H.M.T.G.A., Naumann, R. and Trumbull, R.B. (2015) Hydrothermal mica deposits in altered meta-ultrabasites from north-central Sri Lanka. Journal of Geochemical Exploration, 153, 66-78.

Matsuura, Y., Kehelpannala, K.W. and Wada, H. (2007) Differential thermal analysis of Sri Lankan type vein graphite. Geosciences Reports, Shizuoka University, 34, 7-18.

Mitchell, C.J. (1993) Industrial Minerals Laboratory Manual: Flake graphite. British Geological Survey Technical Report, 30-31.

Nakamura, Y., Oohashi, K., Toyoshima, T., Satish-Kumar, M. and Akai, J. (2015) Strain-induced amorphization of graphite in fault zones of the Hidaka metamorphic belt, Hokkaido, Japan. Journal of Structural Geology, 72, 142-161.

Pimenta, M.A., Dresselhaus, G., Dresselhaus, M.S., Cançado, L.G., Jorio, A. and Saito, R. (2007) Studying disorder in graphite-based systems by Raman spectroscopy. Physical Chemistry Chemical Physics, 9, 1276-1291.

Piumalee, W.D.H., Cooray, J.T. and De-Silva, S.N. (2013) Characterizing of Vein Quartz Occurrences in Sri Lanka with Special Reference to Mahagama, Randeniya, and Illukpelessa. Technical Sessions of Geological Society, $29^{\text {th }}$, Kandy, Sri Lanka, 2013, Extended Abstracts, 25-28.

Silva, K.K.M.W. (1974) Tectonic control of graphite mineralization in Sri Lanka. Geological Magazine. Cambridge University Press, Cambridge, 307-312.

Silva, K.K.M.W. (1987) Mineralization and wall rock alteration at the Bogala graphite deposit, Bulathkohupitiya, Sri Lanka. Economical Geology, 82, 1710-1722.

Simandl, G.J., Paradis, S. and Akam, C. (2015) Graphite deposit types, their origin, and economic significance. Symposium on Strategic and Critical Materials, British Columbia Geological Survey, Columbia, 2015, 163-171.

Simandl, G.J., Paradis, S., Valiquette, G. and Jacob, H.L. (1995) Crystalline graphite deposits, classification and economic potential. Forum on the Geology of Industrial Minerals, $28^{\text {th }}$, Columbia, 1995, 168-174.

Taylor, H.A. (2006) Graphite. In Industrial Minerals and Rocks (Kogel, J.E., Trivedi, N.C., Barker, J.M. and Krukowski, W.T. Eds.). Society for Mining, Metallurgy and Exploration, Inc., Littleton, Colorado, 507-518.

Touzain, Ph., Balasooriya, N.W.B., Bandaranayake, P.W.S.K. and Descolas, G. (2010) Vein Graphite from the Bogala and Kahatagaha-Kolongaha Mines, Sri Lanka, A Possible Origin. The Canadian Mineralogist, 48, 1373-1384.

Tuinstra, F. and Koenig, J.L. (1970) Raman spectrum of graphite. Journal of Chemical Physics, 53, 1126-1130.

Wijayananda, N.P. (1987) The Graphite Industry in Sri Lanka. Science education series 24, Colombo, Natural Resources, Energy and Science Authority, 23-25.

Wijayananda, N.P. and Jayawardana, De.S. (1983) Some aspects of the geology of graphite mineralization in Sri Lanka, with particular reference to the Kahatagaha-Kolongaha Area: Transactions of the Institution of Mining and Metallurgy. Applied Earth Science, 92, 93-98.

Wyckoff, R.W.G. (1963) Crystal Structures. Interscience, 1, 24.

Manuscript received July 21, 2017

Manuscript accepted February 27, 2018

Manuscript handled by Toshiaki Tsunogae 